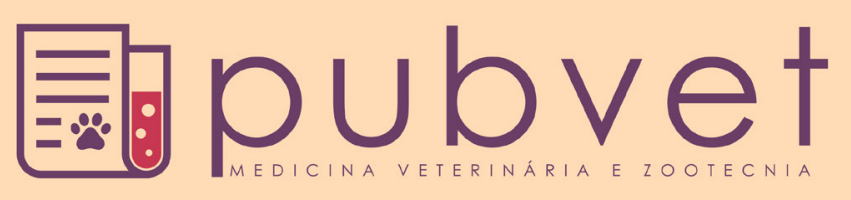

HTTP://DX.DOI.ORG/10.22256/PUBVET.V11N8.775-780

\title{
Desenvolvimento de um transferidor de leite adaptado ao vácuo da ordenha
}

\author{
Edgar Moreira da Silva1, Marcos Aurélio Lopes ${ }^{2 *}$, Milton Ghedini Cardoso ${ }^{3}$
}

${ }^{\prime}$ Extensionista da EMATER - MG, Especialista em Extensão Ambiental para o Desenvolvimento Sustentável, Piranguinho, MG, Brasil. Email: edgarematermg@gmail.com

${ }^{2}$ Professor Titular da Universidade Federal de Lavras, Departamento de Medicina Veterinária, Bolsista do CNPq, Departamento de Medicina Veterinária, Universidade Federal de Lavras, Lavras, MG, Brasil, e-mail:malopes@dmv.ufla.br.

${ }^{3}$ Médico Veterinário, M.Sc.em Ciências Veterinárias, Alfenas, MG, Brasil, e-mail: cardoso_vet@yahoo.com.br

*Autor para correspondência

RESUMO. Objetivou-se analisar a viabilidade do transferidor de leite adaptado à tubulação de vácuo da ordenha, apresentar sua composição, seu funcionamento e indicadores nos aspectos de mão-de-obra e qualidade do leite. A pesquisa foi realizada em uma propriedade rural, no munício de Piranguinho, MG, onde se produz leite com características de agricultura familiar, durante o período de agosto de 2015 até junho de 2016. Os dados foram colhidos através de visitas realizadas na propriedade onde foram feitas entrevistas e observações sobre o uso do equipamento. Foram utilizados resultados de análises de leite, em um período com e sem o uso do transferidor, visando investigar possíveis alterações de qualidade do leite. Dentre os resultados encontrados, destaca-se a confecção do transferidor do leite adaptado ao vácuo da ordenha, com peças de baixo custo. Foi constatada, também, sua funcionalidade no transporte de leite, da sala de ordenha até o tanque de resfriamento, em substituição ao carregamento manual em latões. Não houve alteração significativa da qualidade do leite na contagem bacteriana total, quando se comparado períodos com ou sem o uso do transferidor de leite.

Palavras chave: agricultura familiar, bovinocultura de leite, inovação, qualidade de leite

\section{Development of a milk transfer adapted to the milking machine vacuum}

ABSTRACT. It was intended to study the viability of the milk transfer adapted to the vacuum piping of the milking machine, present its composition, its functioning and indicators in the aspects of labor and milk quality. The study was conducted on a farm in the municipality of Piranguinho - Brazil, where milk is produced with family farming characteristics during the period of August of 2015 to June of 2016. The data were collected through visits performed on farms where interviews and observations about the use of the equipment were done. Results of milk analyses over a period with and without the use of transfer were utilized, aiming to investigate possible alterations of milk quality. Among the results found, the making of the milk transfer adapted to the vacuum milking machine stands out, with low cost pieces. Its functionality in the milk transportation from the milking parlor to the cooling tank was found in substitution to the hand carrying in cans. There was no significant interaction of milk quality in the total bacterial count when compared with the periods with or without milk transfer.

Keywords: Family farming, dairy cattle production, innovation, milk quality 


\section{Desenvolvimiento de un transferidor de leche adaptado al vacío de una ordeñadera mecánica}

RESUMEN. Se tuvo como objetivo analizar la viabilidad del transferidor de leche adaptado a la tubería del vacío de la ordeñadera mecánica, presentar su composición, su funcionamiento e indicadores de aspectos como la mano de obra y la calidad de leche. La investigación fue realizada en una propiedad rural, en el municipio de Piranguinho-Brasil, donde se produce leche con características de agricultura familiar, durante el periodo de agosto del 2015 hasta junio del 2016. Los datos fueron recolectados a través de visitas realizadas en la propiedad donde fueron hechas entrevistas y observaciones sobre el uso del equipo. Fueron utilizados resultados de análisis de leche, en un periodo con y sin uso del transferidor, con la visión de investigar posibles alteraciones de la calidad de la leche. Dentro de los resultados encontrados, se destaca la confección del transferidor de leche adaptado al vacío de la ordeñadera mecánica, con piezas de bajo costo. Fue constatado también, su funcionalidad en el transporte de la leche, de la sala de ordeño hasta el tanque de resfriamiento, en substitución de la cargada manual en cantinas. No hubo alteración significativa de la calidad de la leche en el conteo total de bacterias, cuando fue comparado con periodos con y sin uso del transferidor de leche.

Palabras clave: Agricultura familiar, ganadería de leche, innovación, calidad de leche

\section{Introdução}

O Estado de Minas é o maior produtor nacional, participando com $26 \%$ da produção brasileira em 2015 (ANUALPEC, 2016). A agricultura familiar contribui com cerca de $45 \%$ do valor bruto da produção desempenhando um papel de grande importância social, detendo $79 \%$ dos estabelecimentos rurais do estado e ocupa $62 \%$ do pessoal no meio rural (França et al., 2009). No município de Piranguinho/MG, onde foi desenvolvida a pesquisa, mais de $90 \%$ dos produtores de leite são da agricultura familiar e há problemas no município de falta de mão de obra capacitada para trabalhar nas propriedades leiteiras, principalmente no serviço de ordenha (EMATER-MG, 2016). Em se tratando do valor das despesas com mão de obra, observa-se, ainda, a importância de se reduzi-la nas propriedades leiteiras. De acordo com Lopes et al. (2011), as despesas com mão de obra representam, em média, um percentual de $14,9 \%$ do custo operacional efetivo da atividade leiteira. Nesta situação torna-se importante o desenvolvimento de equipamentos que auxiliem o trabalho dos produtores de leite, principalmente equipamentos de custo mais acessível para os agricultores familiares e que diminuam a necessidade de maior quantidade de pessoas em determinada atividade, ou ainda, que permitam maior inclusão da mão de obra feminina.

Ulbricht and Gontijo (2003) mostraram que a implantação de dutos de leite promoveu significativa diminuição do peso que os trabalhadores carregavam diariamente, o que, com certeza, explica a melhora nas condições de trabalho dos ordenhadores. O transporte de peso, como o leite armazenado em latão, pelo ordenhador, da sala de ordenha até o tanque de resfriamento, torna o trabalho um processo mecanicamente estressante, envolvendo um alto custo energético, devido à tensão exercida sobre os músculos dos braços e das costas durante o transporte dos pesos (Maia et al., 2011).

Em 2011 entrou em vigor a Instrução Normativa IN 62/2011 (BRASIL, 2011), que exige do produtor o atendimento de padrões mínimos de qualidade do leite na composição e no aspecto sanitário, verificada por meio de análises laboratoriais sistemáticas. Assim, no cumprimento desta normativa, pode haver penalização ou bonificação para o produtor. Segundo Teixeira Júnior et al. (2015), a utilização de práticas que possibilitam melhorias na qualidade do leite proporciona um diferencial da remuneração, advinda das bonificações, incrementa os resultados econômico-financeiros e melhora a rentabilidade do sistema de produção de leite. Taffarel et al. (2013) afirmaram que "o leite obtido por utilização de ordenhadeira canalizada e de resfriador a granel apresenta melhor qualidade microbiológica".

Considerando a importância do desenvolvimento de equipamentos com baixo custo de investimento, para a pecuária leiteira, que visam diminuir mão de obra, objetivou-se analisar a viabilidade do transferidor de leite adaptado à 
tubulação de vácuo da ordenha, apresentar sua composição, seu funcionamento e alguns indicadores nos aspectos de mão de obra e qualidade do leite.

\section{Material e Métodos}

Esta pesquisa foi realizada no período de agosto de 2015 a junho de 2016, observando, in loco, os dados utilizados para esta análise, em uma propriedade rural, com mão de obra familiar, produção diária de 600 litros, no município de Piranguinho, Minas gerais.

O estábulo da propriedade é composto por dois cochos laterais onde as vacas são alimentadas, presas a uma corrente pelo pescoço. Nesse mesmo local, ocorre a ordenha conhecida como "balde ao pé". O leite fica previamente armazenado em latões que são colocados próximos às vacas que estão sendo ordenhadas. A sala onde fica o tanque de refrigeração do leite se localiza na extremidade oposta do estábulo em relação à extremidade onde as vacas entram.

A pesquisa se divide em dois cenários. No primeiro, o produtor utilizou o transferidor de leite adaptado ao vácuo da ordenha para transferir o leite da sala de ordenha até o tanque de resfriamento. No segundo, o produtor não utilizou nenhum tipo de transferidor de leite, sendo o leite carregado no próprio latão e elevado até a altura da entrada de leite do tanque e despejado; tudo isso feito de forma manual, na maioria das vezes por duas pessoas. As observações da rotina de trabalho, no aspecto ergonômico durante a realização das tarefas, foram realizadas durante visitas nos horários de ordenhas no período da pesquisa. Nesse momento eram feitas observações e anotações com foco na realização do serviço de transporte interno do leite.

Foram observadas as contagens bacterianas totais apontadas em análises laboratoriais realizados na Clínica do Leite, em Piracicaba, SP. As amostras foram coletadas, diretamente no tanque resfriador, pela empresa que adquire o leite. Os resultados das análises de contagem bacteriana total foram utilizados como indicador de qualidade do leite. Foram computados resultados de um período em que o transferidor de leite estava em uso e de um período em que o transferidor de leite não foi utilizado. Outros dados foram coletados através de entrevistas com o produtor, e demais pessoas que trabalham na ordenha da propriedade.

\section{Resultados e Discussão}

O transferidor de leite adaptado o vácuo da ordenha (Figura 1) foi desenvolvido pelo produtor, utilizando materiais de sua propriedade, utilizados comumente em salas de ordenha que trabalham com o sistema de "ordenha balde ao pé". O transferidor de leite, adaptado ao vácuo da ordenha, é composto pelos seguintes materiais: 1 latão de leite branco semitransparente de $45 \mathrm{~L}$; 1 mangueira de leite (que vai da sala de ordenha a sala do tanque de resfriamento); 1 mangueira de vácuo (que vai do cano de vácuo até a sala do tanque de resfriamento); 1 flange de $1 / 2$ polegada; 1 registro de 1/2 polegada; 1 tampa de latão de inox com no mínimo dois bicos (vácuo e entrada de leite); 1 suporte para o latão (instalado na parede com altura superior à altura da entrada de leite do tanque de resfriamento). As peças utilizadas para a montagem do equipamento apresentam baixo custo em relação a outros tipos de transferidores de leite encontrados no mercado, contribuindo para a redução do custo com depreciação, o que reflete no aumento da rentabilidade (Lopes et al., 2015).

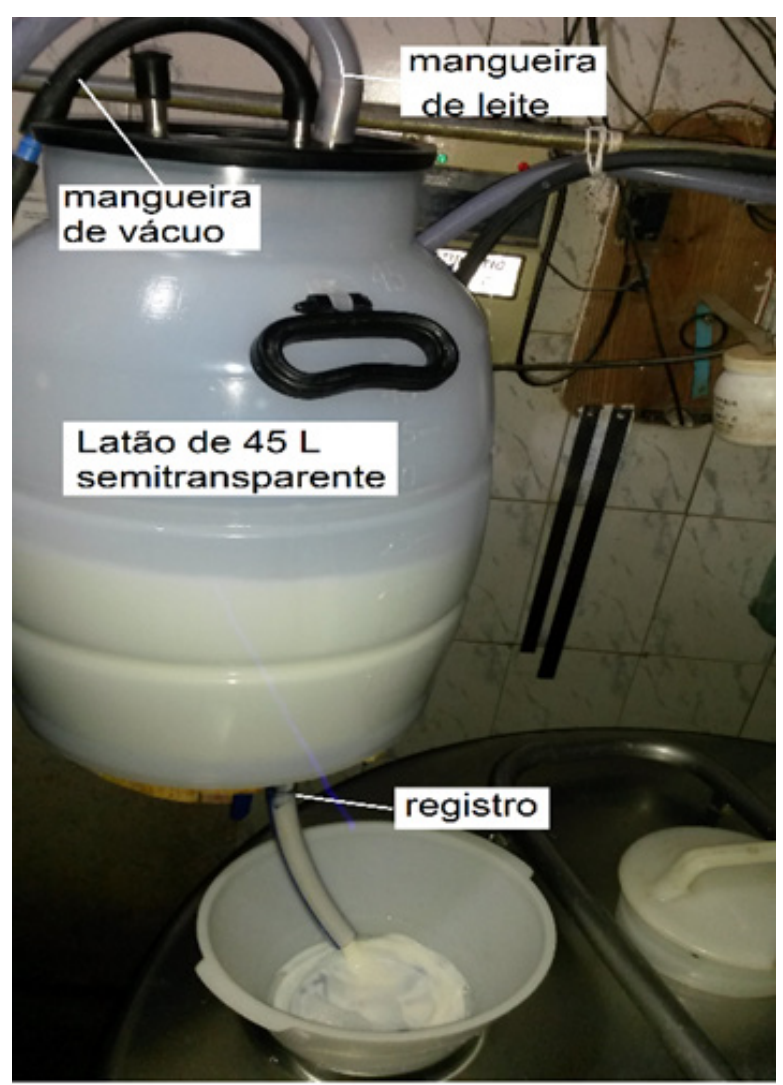

Figura 1. Transferidor de leite adaptado ao vácuo da ordenha. Fonte: Arquivo pessoal do extensionista (2016).

O funcionamento do transferidor se dá pela ligação do latão ao ponto mais próximo do encanamento sistema de "vácuo" da ordenha 
através de uma mangueira. Esse "vácuo" suga o leite da sala de ordenha transportando-o até o latão. A mangueira do leite deve ter uma ponta encaixada na tampa do latão e a outra ponta mergulhada nos latões de leite que estão na sala de ordenha. Com o latão cheio interrompe-se a transferência de leite e abre-se o registro para que o leite caia por gravidade no tanque de resfriamento e libere espaço no latão para transferência de mais leite.

O uso do transferidor de leite adaptado ao vácuo da ordenha evitou que o transporte do leite fosse feito de forma manual e que ocupasse mais de uma pessoa, reduzindo a utilização da mão de obra, com consequente aumento da sua produtividade. Tais fatos contribuem para o aumento da rentabilidade, pois o item mão de obra é o segundo com maior representatividade no custo operacional efetivo da atividade leiteira, ficando atrás apenas da alimentação (Lopes et al., 2004, Lopes et al., 2005, Lopes et al., 2007, Lopes et al., 2008, Carvalho et al., 2009, Santos and Lopes, 2012, Santos and Lopes, 2014, Ferrazza et al., 2015). Além disso, Gonçalves et al. (2008) correlacionaram positivamente a produtividade da mão de obra com a eficiência técnica da atividade leiteira, independentemente do nível de produção, sendo maior para os pequenos produtores $(<50$ litros/dia), o que reflete a importância desse quesito para esse grupo de produtores.

Com a utilização do transferidor de leite o ordenhador não necessitou fazer esforço físico no momento de carregar o leite da sala de ordenha até o tanque de resfriamento em latões. Segundo levantamento de Ulbricht and Gontijo (2003), $85 \%$ dos ordenhadores possuem distúrbios osteomusculares relacionados ao trabalho em alguma região do corpo (costas, membros superiores e membros inferiores). Alguns dos fatores de risco, que predispõem ao desenvolvimento dos distúrbios osteomusculares, são a falta de ergonomia nas atividades do trabalho e o excesso de peso carregado pelo trabalhador (Ulbricht and Gontijo, 2003). O produtor entrevistado, nesta pesquisa, deixou claro que o equipamento facilitou $o$ trabalho em sua propriedade. Ao substituir o esforço físico de carregar os latões de leite, o produtor conseguiu acabar com um dos momentos mais desagradáveis para os ordenhadores de sua propriedade.

A higienização do equipamento é feita na propriedade com água quente, detergente alcalino, detergente ácido e hipoclorito de sódio, da mesma forma que é recomendado para ordenhadeiras do tipo leite canalizado. A instalação e a higienização do equipamento da forma tradicional, não prejudicou a qualidade do leite. Os resultados das análises evidenciam que não houve alterações significativas na qualidade do leite, em relação ao parâmetro contagem bacteriana total, em períodos com (Figuras 2) e sem o uso (Figuras 3) do transferidor de leite.

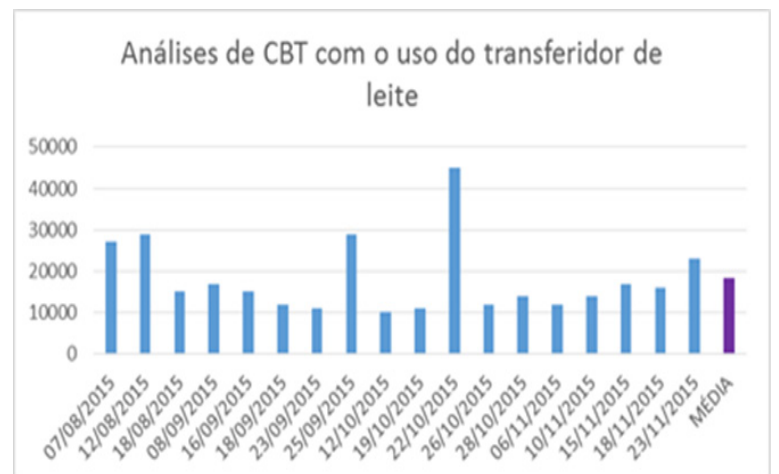

Figura 2. Resultados de contagem bacteriana total (ufc/mL) com o uso do transferidor de leite.

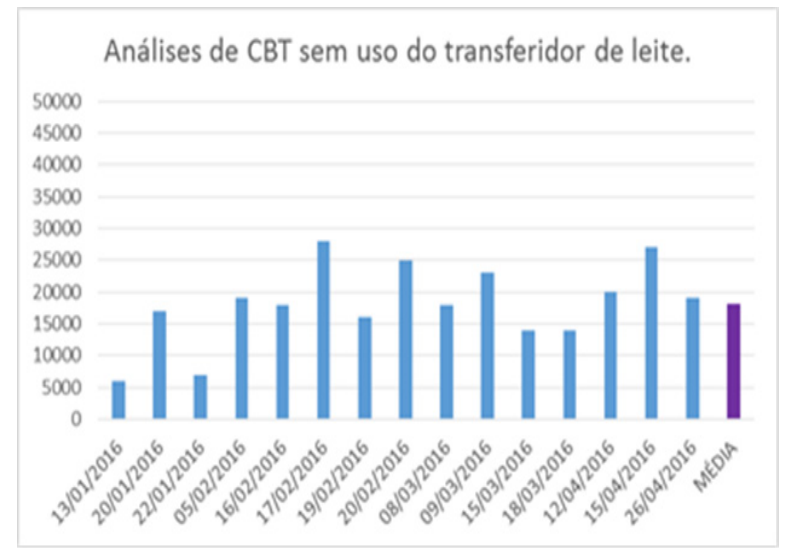

Figura 3. Resultados contagem bacteriana total (ufc/mL) sem o uso do transferidor de leite.

Os 33 resultados utilizados, com e sem o transferidor, indicam que a propriedade estudada possui boa qualidade do leite em se tratando de contagem bacteriana total, apresentando valores bem abaixo das $300.000 \mathrm{ufc} / \mathrm{mL}$, exigidos até o momento pela IN 62/2011 (BRASIL, 2011). A partir de 2018, o valor exigido será de 100.000 $\mathrm{ufc} / \mathrm{mL}$, o que exigirá dos produtores maiores esforços operacionais e de bons equipamentos para evitar a contaminação do leite. A quantidade de amostras garante a qualidade da informação em função de diluir os "picos" de resultados bons e ruins.

Na Figura 4 pode-se observar que houve uma pequena diferença numérica entre as médias dos resultados das análises com e sem o uso do 
transferidor de leite. Esses resultados indicam que não há limitações de uso do transferidor de leite em propriedades que se preocupam com a qualidade do produto no parâmetro contagem bacteriana total.

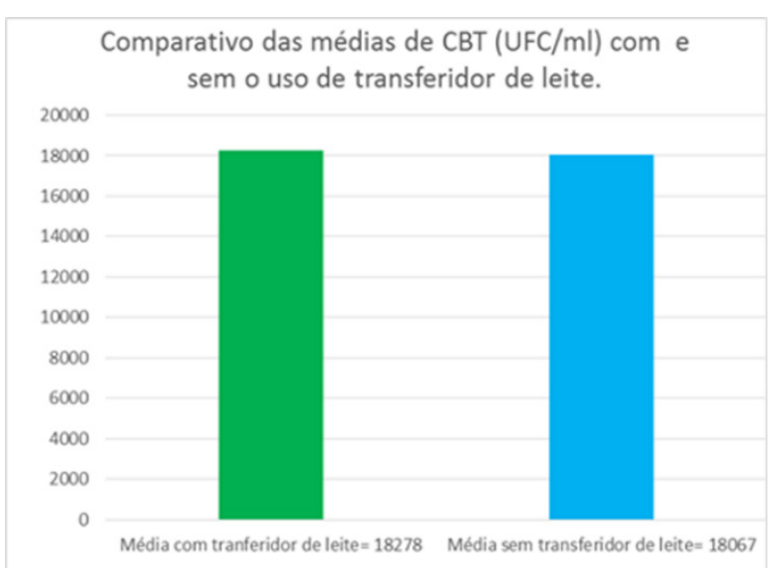

Figura 4. Comparativo de resultados de contagem bacteriana total (ufc/mL), com e sem o uso do transferidor de leite.

\section{Conclusões}

O transferidor de leite adaptado ao vácuo da ordenha é um equipamento que apresenta bons resultados para o produtor de leite, no sentido de diminuir o esforço físico do ordenhador que utiliza o sistema de ordenha do tipo "balde ao pé". O transferidor de leite é um equipamento de fácil instalação e de baixo custo. Tal equipamento demonstrou ser eficiente, substituindo o trabalho de carregar o latão de leite da sala de ordenha até o tanque de resfriamento.

A qualidade do leite não sofreu alterações significativas quando comparados períodos com e sem o uso do transferidor, o que justifica sua empregabilidade em propriedades que visam produzir leite com qualidade.

Faz-se necessário, aprofundar os estudos no sentido de custos e qualidade dos materiais, avaliando o equipamento por períodos mais longos.

O uso do transferidor pode ser recomendado para inúmeras propriedades leiteiras, justificando a substituição do trabalho manual por equipamentos que facilitem a rotina dos ordenhadores, como o transferidor de leite adaptado ao vácuo da ordenha, melhorando, assim, suas condições de trabalho e mantendo a qualidade do leite produzido.

\section{Agradecimentos}

À EMATER - MG, por possibilitar a realização desta pesquisa.

\section{Referências Bibliográficas}

ANUALPEC. 2016. Anuário da Pecuária Brasileira, 20th edn. Instituto FNP, São Paulo, SP, Brasil.

BRASIL. Ministério da Agricultura, Pecuária e Abasteccimento, Intruções Normativas $\mathrm{n}^{\circ} 62$, de 29 de dezembro de 2011. Diário Oficial da União, 30 Dezembro 2011.

Carvalho, F. M., Ramos, É. O. \& Lopes, M. A. 2009. Análise comparativa dos custos de produção de duas propriedades leiteiras, no município de Unaí-MG, no período de 2003 e 2004. Ciência e Agrotecnologia, 33, 17051711.

EMATER. Empresa de Assistência Técnica e Extensão Rural de Minas Gerais. 2016. Relatório de Cadastro Público do Escritório Local de Piranguinho, Minas Gerais.

Ferrazza, R. A., Lopes, M. A., de Moraes, F. \& Pascoti Bruhn, F. R. 2015. Índices de desempenho zootécnico e econômico de sistemas de produção de leite com diferentes níveis tecnológicos. Semina: Ciências Agrárias, 36, 485-496.

França, C. G., Del Grossi, M. E. \& Marques, V. P. M. 2009. El censo agropecuario 2006 y la agricultura familiar en Brasil. MDA, Brasília.

Gonçalves, R. M. L., Vieira, W. d. C., Lima, J. E. \& Gomes, S. T. 2008. Analysis of technical efficiency of milk-producing farms in Minas Gerais. Economia Aplicada, 12, 321-335.

Lopes, J. C. O., Figueirêdo, A. V. d., Lopes, J. B., Lima, D. C. P., Ribeiro, M. N. \& Lima, V. B. S. 2015. Zinco e vitamina $\mathrm{E}$ em dietas para frangos de corte criados em estresse calórico. Revista Brasileira de Saúde e Produção Animal, 16, 350-364.

Lopes, M., Cardoso, M., Demeu, F. \& Dias, A. 2008. Composição de rebanhos bovinos leiteiros: levantamento, estimativa do dimensionamento e da evolução. Boletim da Indústria Animal, 65, 163-167.

Lopes, M. A., Lima, A. L. R., Carvalho, F. M., Reis, R. P., Santos, I. C. \& Saraiva, F. H. 2005. Resultados econômicos de sistemas de produção de leite com diferentes níveis tecnológicos na região de Lavras, MG. Arquivo Brasileiro de Medicina Veterinária $e$ Zootecnia, 57, 485-493. 
Lopes, M. A., Lima, A. L. R., Carvalho, F. M., Reis, R. P., Santos, Í. C. \& Saraiva, F. H. 2004. Controle gerencial e estudo da rentabilidade de sistemas de produção de leite na região de Lavras (MG). Revista Ciência e Agrotecnologia, 28, 883-892.

Lopes, M. A., Santos, G. d., Resende, M. C., Carvalho, F. M. \& Cardoso, M. G. 2011. Estudo da rentabilidade de sistemas de produção de leite no município de Nazareno, MG. Revista Ciência Animal Brasileira, 12, 58-69.

Lopes, P. F., Reis, R. P. \& Yamaguchi, L. C. T. 2007. Custos e escala de produção na pecuária leiteira: estudo nos principais estados produtores do Brasil. Revista de Economia e Sociologia Rural, 45, 567-590.

Maia, L. R., Ferraz, S. P. \& Rodrigues, L. B. 2011. Análise das condições de higiene, conforto e segurança em ambientes de trabalho rurais. Encontro Nacional de Engenharia de Produção. Belo Horizonte.

Santos, G. \& Lopes, M. A. 2012. Indicadores de rentabilidade do centro de custo produção de leite em sistemas intensivos de produção. Boletim de Indústria Animal, 69, 1-11.

Santos, G. \& Lopes, M. A. 2014. Indicadores econômicos de sistemas de produção de leite em confinamento total com alto volume de produção diária. Ciência Animal Brasileira, $15,239-248$.

Taffarel, L. E., Costa, P. B., Oliveira, N. T. E., Braga, G. C. \& Zonin, W. J. 2013. Contagem bacteriana total do leite em diferentes sistemas de ordenha e de resfriamento. Arquivos do Instituto Biológico, 80, 7-11.

Teixeira Júnior, F. E. P., Lopes, M. A. \& Ruas, J. R. M. 2015. Efeito do pagamento por qualidade do leite na rentabilidade da atividade leiteira. Revista do Instituto de Laticínios Cândido Tostes, 70, 24-34.

Ulbricht, L. \& Gontijo, L. A. 2003. Fatores de risco associados à incidência de DORT entre ordenhadores em Santa Catarina. Congresso Brasileiro de Pesquisa Ambientais e Saúde. CBPAS, Santos.

\section{Article History:}

Received 20 April 2017

Accepted 16 May 2017

Available on line 23 June 2017

License information: This is an open-access article distributed under the terms of the Creative Commons Attribution License 4.0, which permits unrestricted use, distribution, and reproduction in any medium, provided the original work is properly cited. 